\title{
Synthesis of yttrium aluminum garnet nanoparticles in confined environment III: Cerium doping effect
}

\author{
Francesco Armetta $^{\mathrm{a}}$, Dariusz Hreniak ${ }^{\mathrm{b}}$, Łukasz Marciniak ${ }^{\mathrm{b}}$, Eugenio Caponetti ${ }^{\mathrm{a}}$, \\ Maria Luisa Saladino ${ }^{\mathrm{a}, *}$ \\ ${ }^{a}$ Dipartimento Scienze e Tecnologie Biologiche, Chimiche e Farmaceutiche - STEBICEF and INSTM UdR - Palermo, Università di Palermo, Viale delle Scienze Bld.17, \\ Palermo I, 90128, Italy \\ ${ }^{\mathrm{b}}$ Department of Spectroscopy of Excited States, Institute of Low Temperature and Structure Research, Polish Academy of Sciences, ul Okólna 2, Wrocław, Poland
}

\section{A R T I C L E I N F O}

\section{Keywords:}

Ce:YAG nanoparticles

Yttria

Ce(III)

Confined environment

w/o microemulsion

Phase composition

\begin{abstract}
A B S T R A C T
Cerium yttrium aluminum garnet (Ce: $\mathrm{YAG}, \mathrm{Ce}_{\mathrm{x}} \mathrm{Y}_{3-\mathrm{x}} \mathrm{Al}_{5} \mathrm{O}_{12}$ ) nanoparticles doped with different cerium amount were obtained by calcining the precursors synthesized via co-precipitation in w/o microemulsion for $1 \mathrm{~h}$ at $900{ }^{\circ} \mathrm{C}$. The structural and morphological properties were investigated by using X-ray Diffraction (XRD), Infrared Spectroscopy (IR) and Transmission Electron Microscopy (TEM) coupled with Energy Dispersive X-ray Spectroscopy (EDS) in order to investigate the effect of doping level on formation and microstructure of obtained nanoparticles. It was found that the composition of the final products strongly depends on the concentration of cerium. The formation of single YAG phase was observed only at $0.5 \%$ cerium. For other concentrations, a mixture of YAG and yttria phases was obtained indicating an effect of the cerium on stabilization of sesquioxide phase. Optical properties of the single phase powder were also investigated in details.
\end{abstract}

\section{Introduction}

For decades, the synthesis of nanoparticles in confined environments such as microemulsions or liquid crystals have been considered one of the best way to tailor the particle size and shape [1-3]. In general, the particle size is influenced by the water/surfactant molar ratio [4], by the water/oil molar ratio and by the temperature, which affect the microstructure environment in the phase diagram [5]. If the crystalline phase of the required material is obtained at high temperature, the precursors prepared in microemulsions can be thermally treated. Experimental data demonstrated that the systems maintain a memory of the microstructure used as nanoreactor influencing the final features of the material [6].

This kind of studies has been performed to obtain YAG (yttrium aluminum garnet, $\mathrm{Y}_{3} \mathrm{Al}_{5} \mathrm{O}_{12}$ ) nanoparticles via co-precipitation of hydroxides in a bicontinuos microemulsions $[7,8]$. The preparation in microemulsion allowed to obtain nanoparticles with well-defined shape, not agglomerated and of smaller size $(10-45 \mathrm{~nm})$ respect to those obtained by using other synthetic procedures. Furthermore, the effect of the thermal treatment on the evolution of precursors toward the formation of YAG phase has been also investigated demonstrating the role of the surfactant in the growth mechanism. The possible growth mechanism of YAG nanoparticles was discussed on the basis of observed particle microstructure and morphology after several thermal treatments [8]. The results indicated that the YAG growth process could be influenced by a not complete oxidation of the surfactant (Cetyltrimethylammonium bromide, CTAB). Moreover, it cannot be excluded the formation of a complex between aluminum ions and the degradation products of surfactant, which could affect the availability of aluminum to participate in the crystallization process.

YAG, whose cubic structure is in the space group Ia-3d, doped with lanthanides ions, is an important material with interesting technological applications in displays, X-ray scintillators, lasers, and white light LED which are nowadays well consolidated [9-13]. Notwithstanding, the interest of researcher is still growing because the optical properties of nanocrystals are expected to be dependent not only on the kind of dopant but also on the synthesis route that may influence particle size, its distribution and morphology [14-17]. In this work, the effect of the cerium amount on structure of YAG nanoparticles prepared in microemulsion has been investigated.

The samples have been prepared in the bicontinuous microemulsion constituted by water/CTAB/1-butanol/n-heptane and calcining the precursors at high temperature. The crystalline habit of the obtained materials has been investigated by using X-ray Diffraction (XRD) and

\footnotetext{
* Corresponding author.

E-mail address: marialuisa.saladino@unipa.it (M.L. Saladino).
} 
Infrared Spectroscopy (IR). The morphology and particles size as well as the elemental composition have been investigated by using Transmission Electron Microscopy (TEM) coupled with an Energy Dispersive X-ray Spectroscopy (EDS). Emission and Excitation spectra, lifetimes and quantum efficiency measurements of the single phase powder have been also carried out

\section{Materials and methods}

\subsection{Materials}

Cetyltrimethylammonium bromide (CTAB, Aldrich $\geq 98 \%$ ), 1-butanol (Aldrich, 99.8\%), n-heptane (Sigma-Aldrich, 99\%), $\mathrm{Y}\left(\mathrm{NO}_{3}\right)_{3} \cdot 6 \mathrm{H}_{2} \mathrm{O}$ (Sigma-Aldrich, 99.8\%), $\mathrm{Al}\left(\mathrm{NO}_{3}\right)_{3} \cdot 9 \mathrm{H}_{2} \mathrm{O}$ (Sigma-Aldrich, 99.8\%), Ce $\left(\mathrm{NO}_{3}\right)_{3} \cdot 6 \mathrm{H}_{2} \mathrm{O}$ (Sigma-Aldrich, 99.99\%), ammonia solution (SigmaAldrich 28\%) and deionized water were used as received. The conductance of deionized water was $<1.5 \mu \mathrm{S} / \mathrm{m}$.

\subsection{Preparation of the nanoparticles}

The precursor synthesis of Ce:YAG nanoparticles at different cerium amount has been performed following the procedure already reported $[7,8]$. The samples have been prepared in the bicontinuous microemulsion R70, resulted the more suitable to obtain separate nanoparticles in the previous studies. The yttrium, aluminum, cerium nitrate solutions ( $30-\mathrm{x}, 50$ and $\mathrm{x} \mathrm{mmol} \mathrm{L}{ }^{-1}$, respectively) were prepared by dissolving proper amounts of $\mathrm{Y}\left(\mathrm{NO}_{3}\right)_{3} \cdot 6 \mathrm{H}_{2} \mathrm{O}, \mathrm{Al}\left(\mathrm{NO}_{3}\right)_{3} \cdot 6 \mathrm{H}_{2} \mathrm{O}$ and $\mathrm{Ce}$ $\left(\mathrm{NO}_{3}\right)_{3} \cdot 6 \mathrm{H}_{2} \mathrm{O}$ in water in order to obtain $0,0.1,0.2,0.5,1.0$ and $2.0 \%$ of cerium atoms with respect to total yttrium plus cerium atoms, according to the formula $\mathrm{Ce}_{\mathrm{x}} \mathrm{Y}_{3-\mathrm{x}} \mathrm{Al}_{5} \mathrm{O}_{12}$.

For each batch, a white hue sol was instantaneously observed as a result of mixing with ammonia microemulsion. A complete precipitation occurred in $12 \mathrm{~h}$. The precipitates were thus filtered and repeatedly washed with water to remove residual ammonia, nitrate ions, and surfactant molecules. The obtained white precipitates were over-night dried at $100{ }^{\circ} \mathrm{C}$, then treated at $900{ }^{\circ} \mathrm{C}$ for $1 \mathrm{~h}$. After calcination, solid pellets were formed. The obtained pellets had a yellowish coloration with tonality influenced by the cerium amount.

\subsection{Characterization techniques}

XRD patterns were acquired by a Philips PW 1050/39 diffractometer in the Bragg-Brentano geometry using Ni-filtered $\mathrm{Cu} \mathrm{Ka}$ radiation ( $\lambda=1.54056 \AA$ ) in the $2 \theta$ range $5-90^{\circ}$ with a step of $0.05^{\circ}$ and a time for step of $5 \mathrm{~s}$. The X-ray generator worked at power of $40 \mathrm{kV}$ and $30 \mathrm{~mA}$, and the resolution of the instrument (divergent and antiscatter slits of $0.5^{\circ}$ ) was determined using $\mathrm{R}-\mathrm{SiO}_{2}$ and $\mathrm{R}-\mathrm{Al}_{2} \mathrm{O}_{3}$ standards free from the effect of reduced crystallite size and lattice defects. The phase identification has been performed by using the X'pert HighScore Software.

The ATR spectra were recorded in the $40-4000 \mathrm{~cm}^{-1}$ range, with a step of $2 \mathrm{~cm}^{-1}$, by using a Bruker Vertex 70 Advanced Research FT-IR Spectrometer equipped with Platinum ATR. The measurements have been performed at $2 \mathrm{hPa}$. Data have been corrected with a scatteringtype baseline.

Transmission Electron Microscopy (TEM) micrographs were acquired by using a JEM-2100 (JEOL, Japan) operating at $200 \mathrm{kV}$ accelerating voltage, equipped with an energy dispersive X-ray spectrometer (EDS, Oxford, UK) suitable for element identification. Each powder was homogeneously dispersed in isopropanol by sonication. A small drop was deposited on a lacey-carbon grid of 300 mesh, and after complete solvent evaporation the nickel-copper grid was introduced into the TEM chamber analysis.

Emission and excitation spectra of the nanoparticles were measured using the FLS980 Fluorescence Spectrometer from Edinburgh Instruments equipped with $450 \mathrm{~W}$ Xenon lamp. Both the excitation and

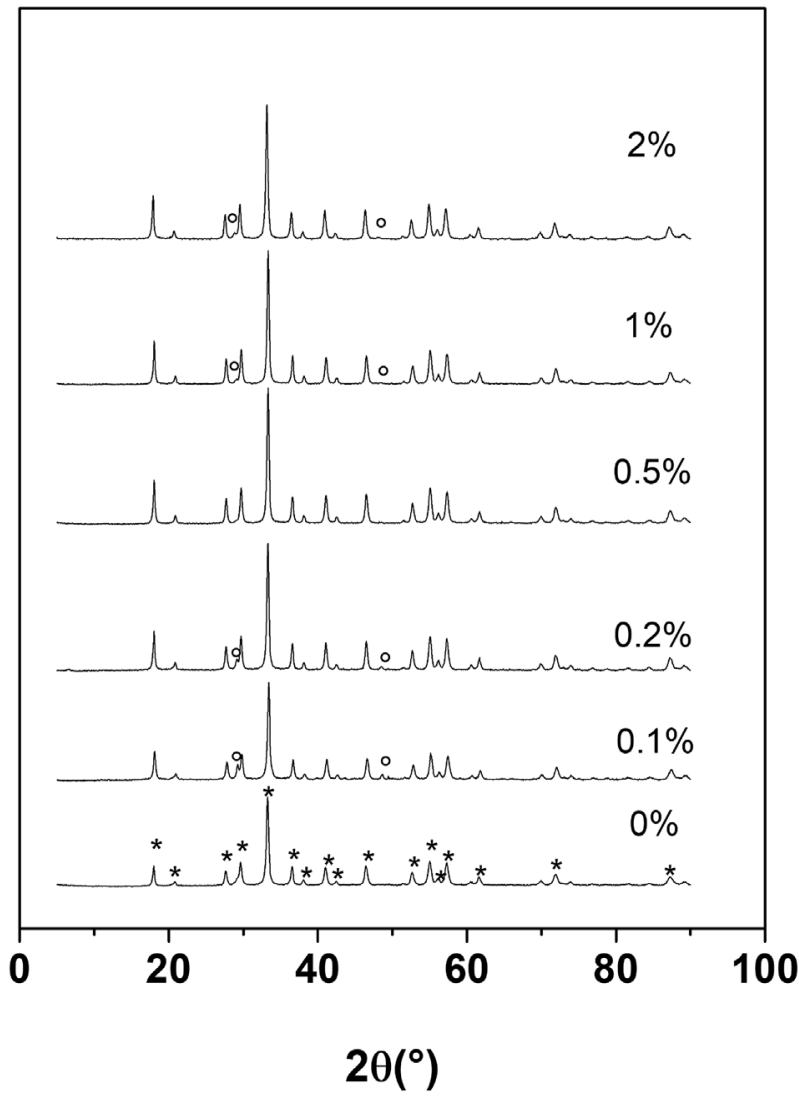

Fig. 1. XRD patterns of the obtained powders. * YAG phase peaks, ${ }^{\circ} \mathrm{Y}_{2} \mathrm{O}_{3}$ phase peaks.

emission $300 \mathrm{~mm}$ focal length monochromators were in Czerny Turner configuration. Excitation arm was supplied with holographic grating of 1800 lines $/ \mathrm{mm}$, blazed at $250 \mathrm{~nm}$, while the emission spectra was supplied with ruled grating, 1800 lines $/ \mathrm{mm}$ blazed at $500 \mathrm{~nm}$. The spectral resolution was $0.1 \mathrm{~nm}$. The R928P side window photomultiplier tube from Hamamatsu was used as a detector.

Quantum efficiency of luminescence was measured using the same equipment supplied with $30 \mathrm{~cm}$ in diameter integrating sphere.

The lifetimes measurements were carried on a femtosecond laser setup composed of a Coherent Libra-S all-in-one ultrafast oscillator and regenerative amplifier laser system, with pulse duration less than $100 \mathrm{fs}$ at $1 \mathrm{kHz}$ repetition rate, a Coherent OPerA-Solo optical parametric amplifier and a Hamamatsu C5677 streak camera with time resolution of 14 ps.

\section{Results and discussion}

Structural and morphological investigation. The XRD patterns of the obtained powders are reported in Fig. 1.

The undoped powder is constituted by single garnet phase $[7,8]$. The XRD patterns of the samples doped with 0.1 and $0.2 \%$ of cerium can be described in terms of two crystalline phases, the garnet phase and the cubic yttrium oxide $\left(\mathrm{Y}_{2} \mathrm{O}_{3}\right.$, yttria) phase, plus a small amorphous component probably constituted by aluminum oxide, usually represented by a typical diffuse profile centred at about $30^{\circ}$ [18], evidenced in this case by an increased background, (see Fig. S1 of the Support Information, S.I). Reflections corresponding to the garnet phase are dominant and evident peaks broadening indicates that crystallites are nanometric sizes.

On the contrary, the powders doped with higher cerium amount are completely crystalline. The powder doped with $0.5 \%$ of cerium is constituted by the single garnet phase. The powders doped with 1 and 
Table 1

Quantitative phase determination, cell parameter $a$, crystallite size D and lattice microstrain for each phase obtained by applying the Rietveld method to the XRD patterns of powders at the different cerium amount.

\begin{tabular}{llllll}
\hline Ce $\%$ & Phases & $\%_{\mathrm{w} / \mathrm{w}}$ & Cell parameter $a(\AA)$ & $\mathrm{D}(\mathrm{nm})$ & Microstrain \\
\hline $\mathbf{0}$ & YAG & $\mathbf{1 0 0}$ & $\mathbf{a}=\mathbf{1 2 . 0 1 8 2 ( 7 )}$ & $\mathbf{5 2 ( 3 )}$ & $\mathbf{0 . 0 0 1 1 5 ( 3 )}$ \\
0.1 & $\mathrm{YAG}$ & $91(2)$ & $\mathrm{a}=12.0249(6)$ & $42(4)$ & $0.00118(6)$ \\
& $\mathrm{Y}_{2} \mathrm{O}_{3}$ & $6(1)$ & $\mathrm{a}=10.6070(1)$ & $42(4)$ & - \\
& amorphous & $3(1)$ & - & - & - \\
0.2 & $\mathrm{YAG}$ & $96(3)$ & $\mathrm{a}=12.0263(4)$ & $50(5)$ & $0.00116(3)$ \\
& $\mathrm{Y}_{2} \mathrm{O}_{3}$ & $4(1)$ & $\mathrm{a}=10.6090(2)$ & $39(4)$ & - \\
& $\mathrm{amorphous}$ & $1.4(4)$ & - & - & - \\
$\mathbf{0 . 5}$ & $\mathrm{YAG}$ & $\mathbf{1 0 0}$ & $\mathrm{a}=\mathbf{1 2 . 0 2 5 9 ( 2 )}$ & $\mathbf{5 0 ( 4 )}$ & $\mathbf{0 . 0 0 1 4 9 ( 1 )}$ \\
1 & $\mathrm{YAG}$ & $98(1)$ & $\mathrm{a}=12.0255(3)$ & $54(5)$ & $0.00153(2)$ \\
& $\mathrm{Y}_{2} \mathrm{O}_{3}$ & $1(2)$ & $\mathrm{a}=10.6430(5)$ & - & - \\
2 & $\mathrm{YAG}$ & $98(2)$ & $\mathrm{a}=12.0262(2)$ & $46(2)$ & $0.00124(2)$ \\
& $\mathrm{Y}_{2} \mathrm{O}_{3}$ & $2(1)$ & $\mathrm{a}=10.6590(4)$ & $35(8)$ & - \\
\hline
\end{tabular}

The error is given in parenthesis. ICDD phase codes used: YAG 01-079-1891, $\mathrm{Y}_{2} \mathrm{O}_{3}$ 00-001-0831.

$2 \%$ of cerium are constituted also by well-defined garnet phase but with a secondary phase. The peak position of this phase can be associated both with the yttria presence $\left(\mathrm{Y}_{2} \mathrm{O}_{3}\right)$ and the cubic phase of cerianite $\left(\mathrm{CeO}_{2}\right)$. Generally, the segregation of the cerianite at higher cerium amount is expected because the $\mathrm{Ce}(\mathrm{III})$ ions are not more soluble in the YAG matrix, due to the large ionic radius of Ce(III) $[19,20]$. However, the intensity ratio between peaks at $29^{\circ}$ and $48^{\circ}$ is typical of yttria phase for both samples (see Fig. S2 of S.I.), indicating that the secondary phase is yttria and not cerianite. This behavior is certain unexpected and different in respect to the conventional ones [19,20].

In order to better discuss the diffraction patterns of samples, the XRD patterns of the powders were analyzed according to the Rietveld method [21] by using the MAUD software [22]. The Rietveld best fit well reproduces the diffraction patterns of each sample. The agreement between experiment and model has been evaluated by $R_{w p}$, (in most of the cases below 5\%). XRD patterns, the correspondent Rietveld fits and the residual plots are shown in Fig. S1 of the S.I. The results of the quantitative phase determination together with the cell parameter for each phase, crystallite size and lattice microstrain are reported in Table 1.

The samples doped with 0.1 and $0.2 \%$ of cerium contain a significant quantity of yttria ( 6 and 4\%), while the samples doped with 1 and $2 \%$ of cerium contain a very low quantity of yttria ( 1 and $2 \%$ ). The sample with $0.5 \%$ of cerium is constituted by the single garnet phase, with a cell parameter value equal to $12.0259 \AA$, higher than the undoped reference obtained at the same temperature (12.0182 $\AA$ ). This, together with the higher microstrain, is an indication of the presence of cerium into the garnet lattice. The cell parameters of the YAG and yttria phases as function of cerium amount are reported in Fig. 2.

The YAG lattice parameter increases with the cerium amount until to $0.5 \%$, and it is ascribable to the cerium substitution of yttrium into the garnet lattice, as other authors observed [19,23]. The lattice parameter in the powders doped with 1 and $2 \%$ is unvaried in respect to the ones of the powder doped at $0.5 \%$, pointing out at the insolubility of cerium ions at higher amount. On the contrary, the yttria lattice parameter increases $\left(\mathrm{a}_{\mathrm{y} t \text { tria }}=10.599 \AA\right.$, ICDD code 00-001-0831) and we can assume that the presence of Cerium (III), not more soluble in the garnet phase, leads to the formation of yttria phase where is more soluble (due to greater ionic radius).

For all samples the calculated YAG crystallite size is similar indicating that this parameter is not affected by the cerium amount.

In order to understand the role of cerium in phase formation, infrared spectra have been acquired. The ATR spectra of Ce:YAG powders are shown in Fig. 3.

No band of $\mathrm{O}-\mathrm{H}$ vibrations is present in the range $4000-1000 \mathrm{~cm}^{-1}$ (Fig. S3 in the S.I.). In the range $1000-40 \mathrm{~cm}^{-1}$ the same vibration

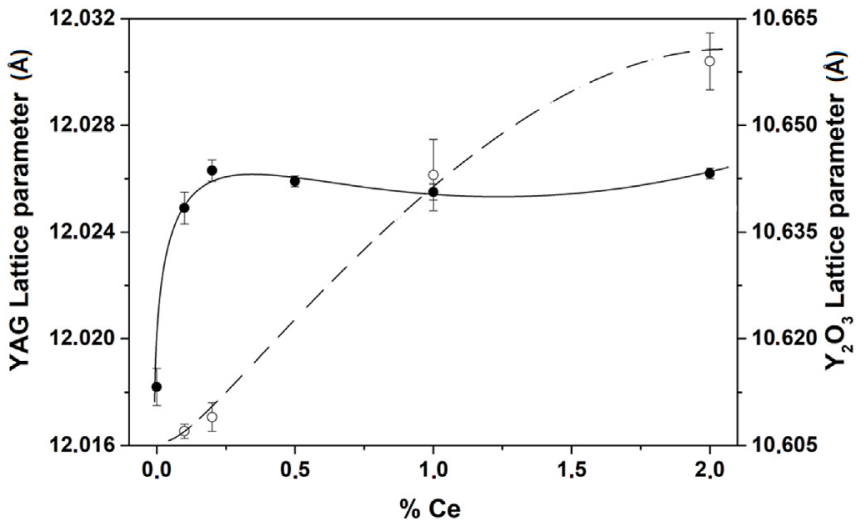

Fig. 2. Cell parameter of YAG $(\bullet)$ and yttria $(O)$ phases as function of cerium amount. Lines are guide eye only.

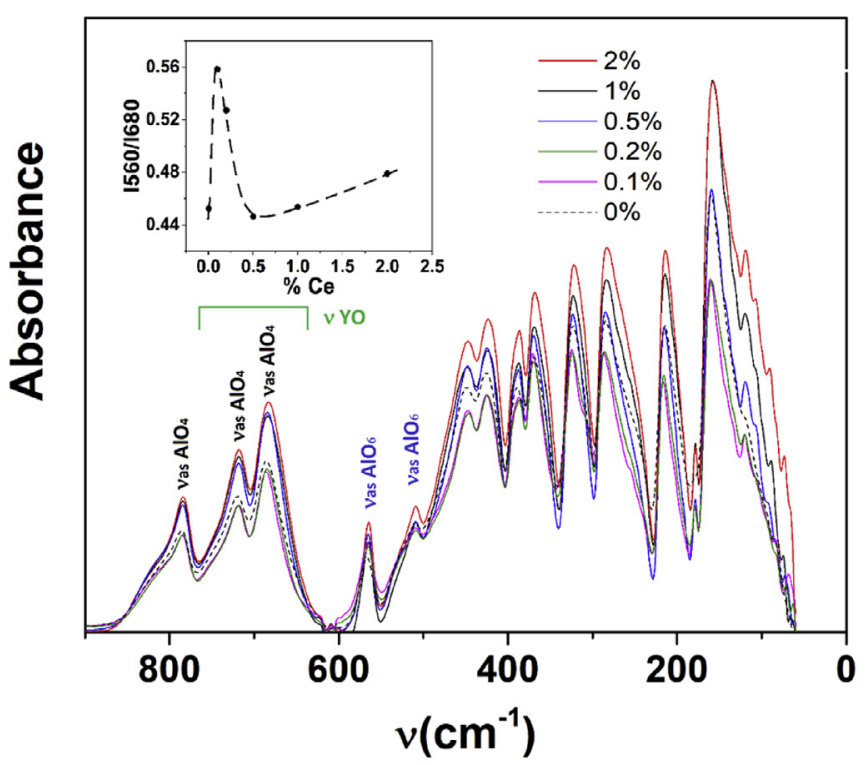

Fig. 3. ATR spectra of powders at different cerium amount. Inset: $I_{560} / I_{680}$ values vs cerium amount. Inset line is guide eye only.

bands are present in all spectra. The peak profiles are sharp, which may be due to an high order degree of cations, in terms of the lattice positions, according to diffraction observations. The peak assignment indicates the presence of all characteristic one-phonon region vibration modes of YAG crystal. The peaks between 790 and $650 \mathrm{~cm}^{-1}$ represent the characteristic Al-O metal-oxygen vibrations of tetrahedral aluminum oxide, while the peaks between 600 and $90 \mathrm{~cm}^{-1}$ represent the characteristic $\mathrm{Al}-\mathrm{O}$ metal-oxygen and $\mathrm{Y}-\mathrm{O}$ metal-oxygen of cations octahedrally coordinated [24]. However, the characteristic yttria peaks often recognized between 600 and $560 \mathrm{~cm}^{-1}$ are covered by YAG bands [25]. In order to get light to this aspect, the intensity ratio between the band at $560 \mathrm{~cm}^{-1}$ (Y-O) and the ones at $680 \mathrm{~cm}^{-1}$ of tetrahedral Al-O, $\left(\mathrm{I}_{560} / \mathrm{I}_{680}\right.$ ), was calculated. The $\mathrm{I}_{560} / \mathrm{I}_{680}$ values are reported vs the cerium amount in the inset of Fig. 3 . The trend has two minimum values for 0 and $0.5 \%$ of cerium, indicating that the sample is a pure garnet phase doped at $0.5 \%$. The $\mathrm{I}_{560} / \mathrm{I}_{680}$ higher values obtained for the other samples, reflecting the number of Y-O vibration respect to the tetrahedral aluminum ones, are another validation supporting the formation of the yttria phase in agreement with the XRD data. This effect is more evident for the samples doped at 0.1 and $0.2 \%$ (see maximum in the inset in Fig. 3) which contain the highest amount of yttria phase.

A small peak at $180 \mathrm{~cm}^{-1}$ is present only in the spectra of powders containing cerium. No similar evidences are present in literature cause 


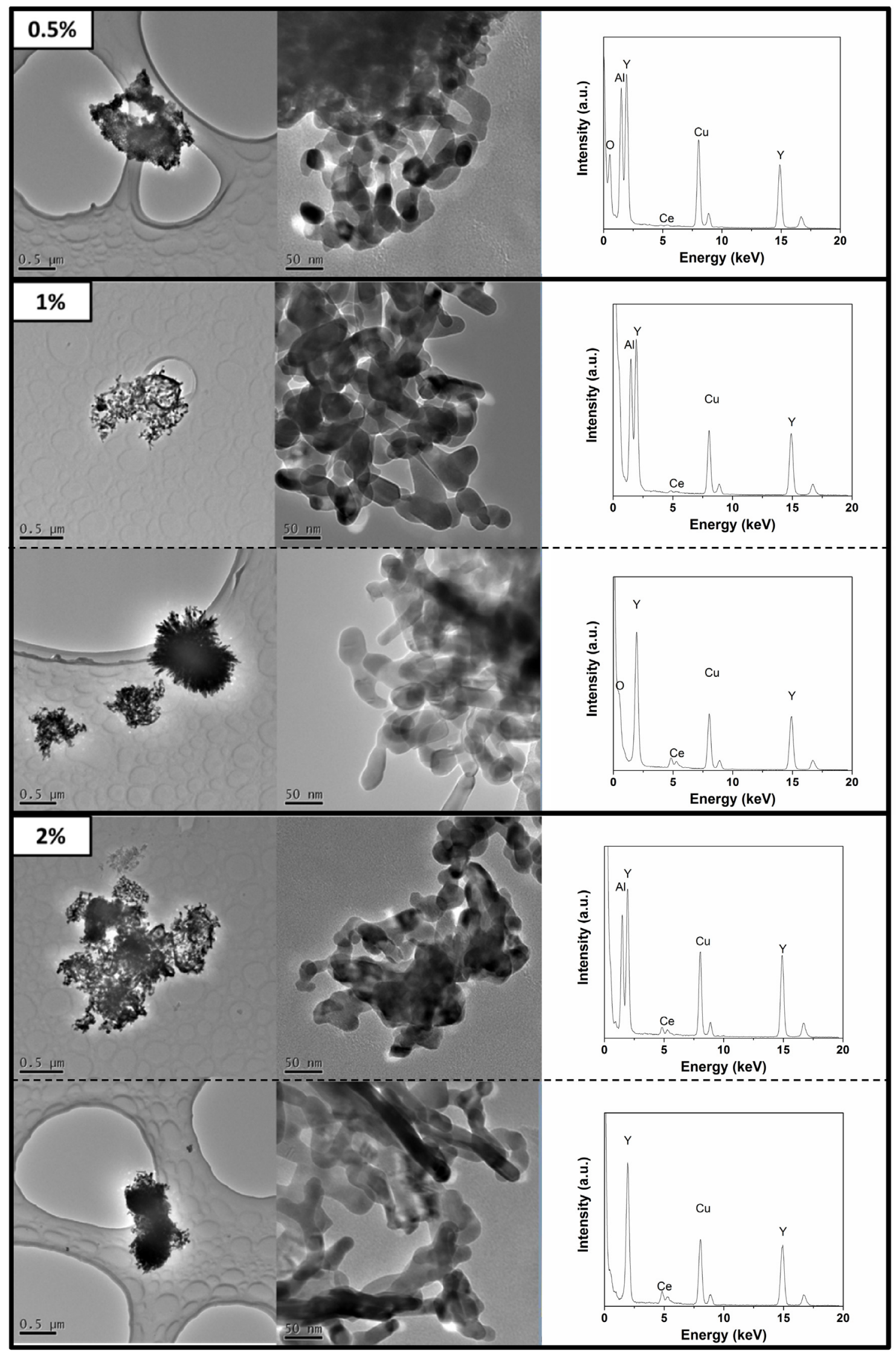

Fig. 4. TEM micrographs and EDS spectra of the powders doped with $0.5,1$ and $2 \%$ of cerium. 
of the extremely low wavenumber. It could be attributed to the one of the $\mathrm{Ce}-\mathrm{O}$ vibration mode.

In addition, on increasing the cerium amount, a small shift of the peak profiles toward lower wavenumbers is found. This shift indicates a mass increase in the bond involved in the vibration mode, because the frequency of vibration is inversely proportional to mass of vibrating molecule. It is justified because of substitutions of yttrium with heavier cerium ions, as already observed in literature [26].

TEM investigation was performed in order to investigate the morphology and to evaluate the particle size. Chosen TEM micrographs at different magnifications and EDS analysis of the powders at cerium amount $0.5,1$ and $2 \%$ are reported in Fig. 4. TEM micrographs exhibit similar morphologies and sizes ( $\sim 35 \mathrm{~nm}$ on average) of the observed objects at the different cerium amount, similar to the un-doped YAG obtained in the same conditions of microemulsion assisted synthesis $[7,8]$. However, in some cases the particles agglomeration is different. The sample of powder doped with $0.5 \%$ of cerium is constituted by clusters of particles randomly distributed. After increasing the cerium amount (to 1 and $2 \%$ ), clusters randomly distribute and produce structures of hedgehog shape, already identified in the study on the effect of thermal treatment [8]. For better understanding the nature of all observed objects the EDS analysis was performed. It was found that the agglomerates were constituted by aluminum, yttrium and cerium, while only yttrium and cerium are present in hedgehogs. This result, according to XRD and IR data analysis, evidences the distribution of cerium both in YAG and yttria particles. The higher amount of cerium, not more soluble in the garnet phase, is segregated from the YAG crystals, which maintain the same cell parameter, and thus solubilized in the yttria phase.

These findings, arising from XRD, ATR and TEM-EDS data, could be explained taking into account the methodology of preparation and in particular the surfactant presence during the synthesis of the precursors and the byproducts presence during the thermal treatment. We have previously demonstrated that in the microemulsion assisted synthesis, where the surfactant interacts with the ions in the hydroxide precursors, not only this influences the final particle size, but also the mechanism of formation and growth, favoring and stabilizing the yttria phase, at the beginning of the crystals formation [8]. An entrapment of the byproduct within the amorphous matrix has been suggested together with the formation of a complex between aluminum ion and bromide due to their Lewis acid-base properties. On the other hand, Goworek et al. demonstrated the role of aluminum in the CTAB decomposition in mesoporous sieves where a weak dealumination has been observed during the thermal treatment [27] modifying the kind of products of decomposition. In presence of aluminum a part of CTAB molecules is transformed into various chemical species, mainly trimethylamine and 1-hexadecene, which bound to the surface and are transformed only after desorption. The total desorption of amine species requires high temperature.

On the other hand, the cerium content affects the evolution of the crystalline phases, also at small concentrations, reaching a good quality of the powder with the formation of the pure Ce:YAG nanoparticles at $0.5 \%$. In presence of high amount of cerium, the surfactant and its decomposition byproduct (in gaseous phase or adsorbed in the powder) and in particular the bromide, could avoid the cerium oxidation [28-30].

It means that it could be a peculiarity of this kind of synthesis because, by using other procedures of synthesis, the cerium is segregated as Ce(IV) in the cubic cerianite. Since the knowing of the mechanisms of CTAB decomposition is out of the scope of this work, it has not been deepened. On the basis of the above results it will be investigated in a separated work.

Optical properties. The optical properties of the single phase have been thus investigated. The excitation and emission spectra of the single phase powder are reported in Fig. 5.

The excitation spectrum consists of two characteristic for $\mathrm{Ce}^{3+}$ ions

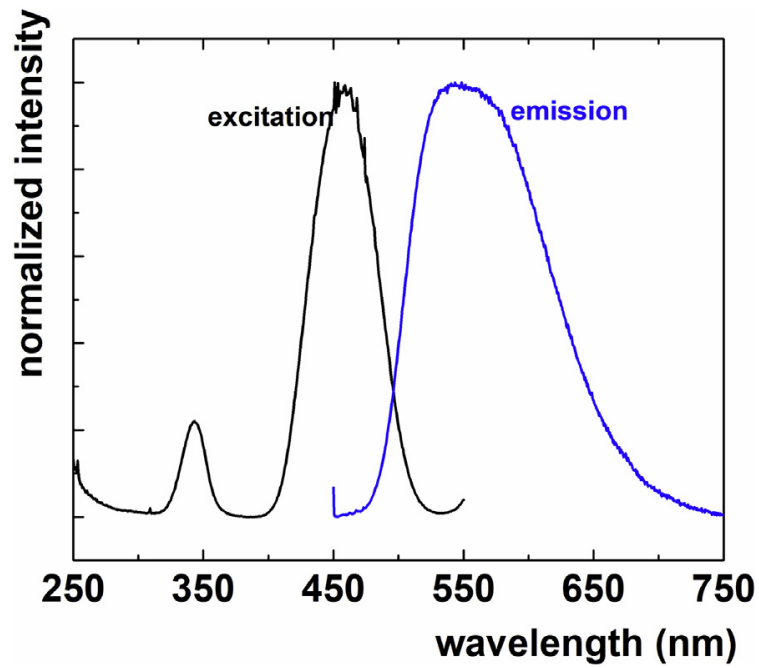

Fig. 5. Excitation and emission spectra of the powder doped with $0.5 \%$ of cerium.

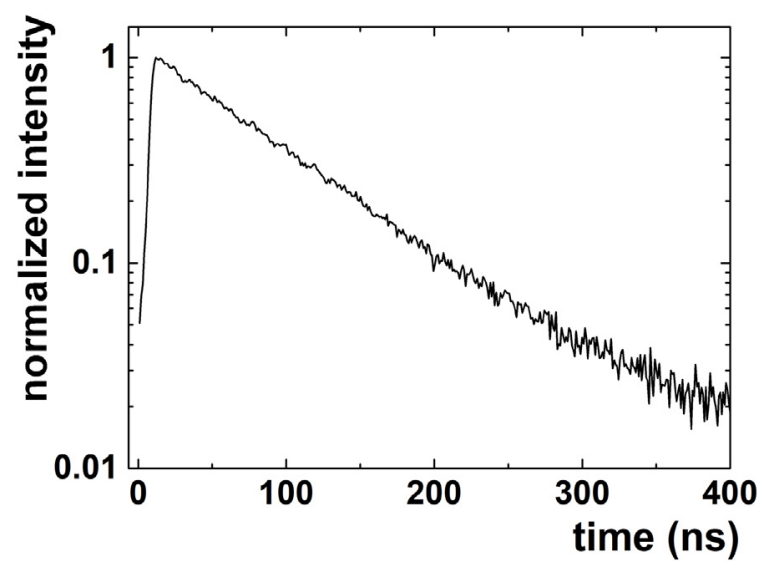

Fig. 6. Room temperature luminescence decay profiles of $\mathrm{Ce}^{3+}$ ions of the powder doped with $0.5 \%$ of cerium.

absorption bands centred at $340 \mathrm{~nm}$ and $460 \mathrm{~nm}$ assigned to ${ }^{2} \mathrm{~F}_{5 / 2} \rightarrow 5 \mathrm{~d}^{1}$ electronic transition. Emission spectrum upon $450 \mathrm{~nm}$ excitation reveals the presence of inhomogeneously broadened emission that consists of two bands related with $5 d \rightarrow{ }^{2} \mathrm{~F}_{5 / 2}$ and $5 \mathrm{~d} \rightarrow{ }^{2} \mathrm{~F}_{7 / 2}$ electronic transition of $\mathrm{Ce}^{3+}$ ions.

The analysis of the kinetics of excited state of $\mathrm{Ce}^{3+}$ ions reveals that the decay profile is a simple single exponential of $\tau=83 \mathrm{~ns}$, which indicates that the cerium ions provide additional channels of nonradiative depopulation of $5 \mathrm{~d}^{1}$ state. The significantly longer decay time of nanosized Ce:YAG in respect to the single crystal counterpart ( $\tau=63 \mathrm{~ns}$ ) [31] results from the difference of the refractive index of nanocrystal (effective refractive index) and crystal according to the Meltzer model [15] (see Fig. 6).

The measured quantum efficiency of the powder doped with $0.5 \%$ was found to be $55 \%$. The lowering of the QY in respect to the commercially available micropowder is related to the nonradiative processes which effectively affect the emission intensity in nanoparticles due to the large surface to core ions ratio. Since the operating temperature may reach $300{ }^{\circ} \mathrm{C}$ in a real device, understanding of how the emission intensity of Ce:YAG nanocrystals doped at $0.5 \%$ is affected by the temperature is a key point (Fig. 7). As it can be noticed, emission intensity is quenched by the temperature reaching $50 \%$ of its initial intensity at $300{ }^{\circ} \mathrm{C}$. Obtained results are in agreement with the trends observed for the commercial Ce:YAG micropowder [32]. 


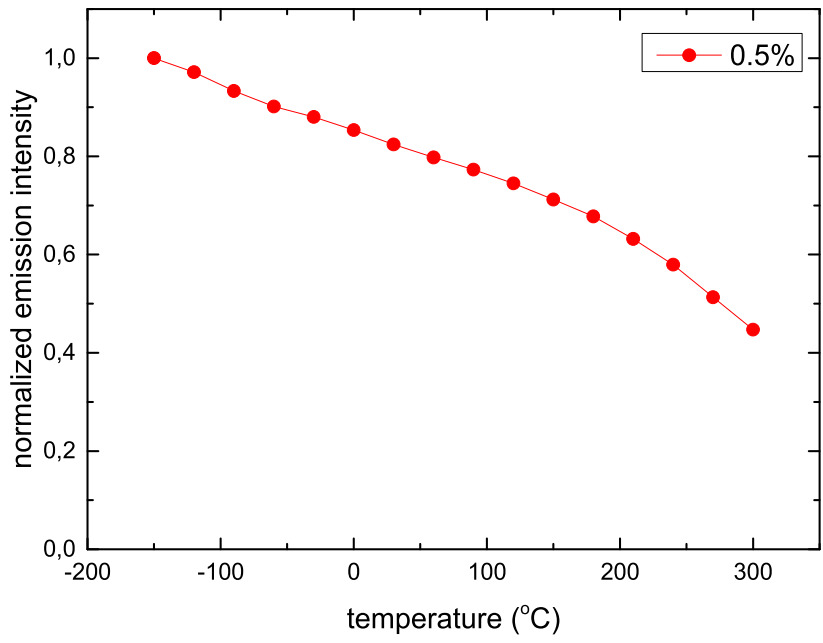

Fig. 7. Emission intensity of the powders at $0.5 \%$ of cerium as function of temperature.

\section{Conclusions}

Ce:YAG nanoparticles characterized by different concentration of cerium have been obtained via co-precipitation in microemulsion. Composition, structure, microstructure, morphology of phases and the optical properties have been investigated for all obtained samples of materials.

The microstructure properties of YAG obtained from the XRD patterns line broadening analysis incorporated in the Rietveld method were in reasonable agreement with IR data and the morphology of particles assessed by TEM. The dopant presence was confirmed by means of EDS analysis.

The obtained results indicate that the presence of cerium affects the formation of the garnet phase, in a different way respect to the traditional one. The single garnet phase doped with cerium was found only for the sample doped with $0.5 \%$. The presence of yttria was recognized in the other samples. It was found also, that, at higher cerium amounts, the insoluble Ce(III) is not segregated in the final product as cerianite, but stabilized the yttria nuclei formation loaded with cerium. The mechanism of formation is influenced by the presence of the surfactant and by its decomposition. On one side the aluminum is slowly sequestered by the decomposition byproducts favoring the yttria formation, on the other side the Ce(III) oxidation is inhibited by the presence of bromide. The optical properties of the single phase powder are typical of Ce:YAG nanoparticles.

\section{Acknowledgments}

M.L.S. thanks University of Palermo for supporting this research through the CORI2016 (Bando per la concessione di contributi per l'avvio e lo sviluppo di collaborazioni dell'Ateneo 2016 - Azione D CORI-2016-D-D15-180463).

D.H. and L.M. acknowledge the Polish National Science Centre for the OPUS 11 2016/21/B/ST5/02385 project.

TEM-EDS experimental data were provided by Centro Grandi Apparecchiature - ATeN Center - Università di Palermo funded by P.O.R. Sicilia 2000-2006, Misura 3.15 Azione C Quota Regionale.

\section{Appendix A. Supplementary data}

Supplementary data related to this chapter can be found at https:// doi.org/10.1016/j.optmat.2018.08.060.

\section{References}

[1] M. Li, H. Schnablegger, S. Mann, Coupled Synthesis and Self-assembly of Nanoparticles to Give Structures with Controlled Organization Nature vol 402 , (1999), pp. 393-395.

[2] J. Eastoe, M.J. Hollamby, L. Hudson, Recent advances in nanoparticle synthesis with reversed micelles, Adv. Colloid Interface Sci. 5 (2006) 128-130.

[3] A.J. Zarur, J.Y. Ying, Reverse Microemulsion Synthesis of Nanostructured Complex Oxides for Catalytic Combustion Nature vol 403, (2000), pp. 65-67.

[4] F. Debuigne, L. Jeunieau, M. Wiame, J.B. Nagy, Synthesis of organic nanoparticles in different W/O microemulsions, Langmuir 16 (20) (2000) 7605-7611.

[5] S. Santra, R. Tapec, N. Theodoropoulou, J. Dobson, A. Hebard, W. Tan, Synthesis and characterization of silica-coated iron oxide nanoparticles in Microemulsion: the effect of nonionic surfactants, Langmuir 17 (10) (2001) 2900-2906.

[6] F. Armetta, M.L. Saladino, D. Chillura Martino, P. Livreri, M. Berrettoni, E. Caponetti, Synthesis of Yttrium Aluminum Garnet nanoparticles in confined environment II: role of the thermal treatment on the composition and microstructural evolution, J. Alloy. Comp. 719 (2017) 264-270.

[7] E. Caponetti, D. Chillura Martino, M.L. Saladino, C. Leonelli, Preparation of Nd:YAG nanopowder in a confined environment, Langmuir 23 (7) (2007) 3947-3952.

[8] F. Armetta, D.F. Chillura Martino, R. Lombardo, M.L. Saladino, M. Berrettoni, E. Caponetti, Synthesis of Yttrium Aluminum Garnet nanoparticles in confined environment, and their characterization, Colloid. Surface. Physicochem. Eng. Aspect. 511 (2016) 82-90.

[9] S.C. Allen, A.J. Steckl, A nearly ideal phosphor-converted white light-emitting diode, Appl. Phys. Lett. 92 (2008) 143309.

[10] A. Ikesue, T. Kinoshita, K. Kamata, K. Yoshida, Fabrication and optical properties of high-performance polycrystalline Nd:YAG ceramics for solid-state lasers, J. Am. Ceram. Soc. 78 (4) (1995) 1033-1040.

[11] E. Zych, C. Brecher, A.J. Wojtowicz, H. Lingertat, Luminescence properties of Ceactivated YAG optical ceramic scintillator materials, J. Lumin. 75 (3) (1997) 193-203.

[12] V. Bachmann, C. Ronda, A. Meijerink, Temperature quenching of yellow $\mathrm{Ce}^{3+}$ luminescence in YAG: Ce, Chem. Mater. 21 (10) (2009) 2077-2084.

[13] X. Ma, X. Li, J. Li, C. Genevois, B. Ma, A. Etienne, C. Wan, E. Véron, Z. Peng, M. Allix, Pressureless glass crystallization of transparent yttrium aluminum garnetbased nanoceramics, Nat. Commun. 9 (1) (2018) art. no. 1175.

[14] J.A. Capobianco, F. Vetrone, T. D'Alesio, G. Tessari, A. Speghini, M. Bettinelli, Optical spectroscopy of nanocrystalline cubic $\mathrm{Y}_{2} \mathrm{O}_{3}: \mathrm{Er}^{3+}$ obtained by combustion synthesis, Physiol. Chem. Phys. 2 (2000) 3203.

[15] R.S. Meltzer, S.P. Feofilov, B. Tissue, H.D. Yuan, Dependence of fluorescence lifetimes of $\mathrm{Y}_{2} \mathrm{O}_{3}: \mathrm{Er}^{3+}$ nanoparticles on the surrounding medium, Phys. Rev. B 60 (1999) 14012.

[16] M.L. Saladino, E. Caponetti, Coprecipitation synthesis of Nd:YAG nanopowders II: the effect of Nd dopant addition the on luminescence properties, Opt. Mater. 32 (2009) 89-93.

[17] C. Chien-Chih, T. Ming-Shyong, H. Min-Hsiung, Luminescent properties of ceriumactivated garnet series phosphor: structure and temperature effects, J. Electrochem. Soc. 155 (6) (2008) B517-B520.

[18] E. Caponetti, M.L. Saladino, F. Serra, S. Enzo, Co-precipitation synthesis of Nd: YAG nano-powders: the effect of $\mathrm{Nd}$ dopant addition with thermal treatment, J. Mater. Sci. 42 (2007) 4418-4427.

[19] M.L. Saladino, E. Caponetti, D. Chillura Martino, S. Enzo, G. Ibba, Effect of the dopant selection (Er, Eu, Nd or Ce) and its quantity on the formation of yttrium aluminum garnet nanopowders, Opt. Mater. 31 (2008) 261-267.

[20] Y.C. Kang, W. Lenggoro, S.B. Park, K. Okuyama, YAG: Ce phosphor particles prepared by ultrasonic spray pyrolysis, Mater. Res. Bull. 35 (2000) 789.

[21] R.A. Young (Ed.), The Rietveld Method, University Press, Oxford, 1993.

[22] L. Lutterotti, S. Gialanella, X-ray diffraction characterization of heavily deformed metallic specimens, Acta Mater. 46 (1998) 101.

[23] X. He, X. Liu, R. Li, B. Yang, K.i Yu, M. Zeng, R. Yu, Effects of local structure of $\mathrm{Ce}^{3+}$ ions on luminescent properties of $\mathrm{Y}_{3} \mathrm{Al}_{5} \mathrm{O}_{12}$ :Ce, Nanoparticles Scientific Reports 6 (2016) 22238.

[24] G.A. Slack, D. Oliver, R.M. Chrenk, S. Roberts, Optical absorptiort of $\mathrm{Y}_{3} \mathrm{Al}_{5} \mathrm{O}_{12}$ from 10 to $50000 \mathrm{~cm}^{-1}$ wavenumbers, Phys. Rev. 3 (1969) 177.

[25] R. Srinivasan, R. Yogamalar, A. Chandra Bose, Structural and optical studies of yttrium oxide nanoparticles synthesized by co-precipitation method, Mater. Res. Bull. 45 (2010) 1165-1170.

[26] M. Veith, S. Mathur, A. Kareiva, M. Jilavi, M. Zimmera, V. Huch, Low temperature synthesis of nanocrystalline $\mathrm{Y}_{3} \mathrm{Al}_{5} \mathrm{O}_{12}$ (YAG) and Ce-doped $\mathrm{Y}_{3} \mathrm{Al}_{5} \mathrm{O}_{12}$ via different sol-gel methods, J. Mater. Chem. 9 (1999) 3069-3079.

[27] J. Goworek, A. Kierys, W. Gac, A. Borówka, R. Kusak, Thermal degradation of CTAB in as-synthesized MCM-41, J. Therm. Anal. Calorim. 96 (2009) 375-382.

[28] Y. Pan, M. Wu, Q. Su, Comparative investigation on synthesis and photoluminescence of YAG: Ce phosphor, Mater. Sci. Eng. B 106 (2004) 251-256.

[29] A.M. Zhabotinskii, A.M. Zaikin, A.B. Rovinskii, Oscillatory oxidation of cerium (III) ions by bromate in a flow system with a controlled inlet of bromide ion, React. Kinet. Catal. Lett. 20 (1982) 29-33.

[30] A. Katafias, Kinetics and mechanism of bromide ions oxidation by cerium(IV) in sulphuric acid solutions revisited, Transition Met. Chem. 31 (2006) 907-911.

[31] E. Zych, C. Brecher, J. Glodo, Kinetics of cerium emission in a YAG: Ce single crystal: the role of traps, J. Phys. Condens. Matter 12 (8) (2000) 1947-1958.

[32] X. Zheng, H. Luo, J. Liu, P. Liu, X. Yu, $\mathrm{Sr}_{3} \mathrm{AlO}_{4} \mathrm{~F}: \mathrm{Ce}^{3+}$ based yellow phosphors: structural tuning of optical properties and use in solid-state white lighting, J. Mater. Chem. C 1 (2013) 7598-7607. 